\title{
Atores Sociais na Política Externa Chilena: o Caso da Aliança do Pacífico
}

\author{
Societal actors in the Chilean Foreign Policy: the Case of the Pacific Alliance
}

\author{
Marcelino Teixeira Lisboa ${ }^{2}$
}

\section{RESUMO}

O texto investiga a participação de atores não governamentais no processo decisório da política externa chilena, na fase de tramitação e aprovação do tratado da Aliança do Pacífico no âmbito político institucional. Verificou-se a participação do empresariado, principalmente nas fases decisórias que concernem ao executivo. Na fase legislativa não houve a participação direta das entidades organizadas do empresariado, mas de think tanks ligados aos partidos políticos $e$ instituições vinculadas à academia.

Palavras chave: Política Externa; Chile; Aliança do Pacífico.

\section{ABSTRACT}

The article investigates the participation of non-governmental actors in the decision-making process of the Chilean foreign policy, in the processing and approval phase of the treaty of the Pacific Alliance in the political institutional framework. It was the participation of the business community, especially in the decisive phases that concern the executive. In the legislative phase, there was no direct action of the entrepreneurs, but think tanks linked to political parties and institutions of the academy.

Keywords: Foreign Policy; Chile; Pacific Alliance.

\section{INTRODUÇÃO}

A política externa, entendida como a parte da política geral, formada pelo conjunto de decisões e atuações mediante as quais se definem objetivos e se utilizam os meios de um Estado para gerar, modificar ou suspender suas relações com outros atores da sociedade internacional, é uma atividade que envolve tanto atores estatais como agentes não governamentais. Em países que adotam um modelo de governo democrático, tal qual o Chile, a política externa frequentemente pode ser caracterizada por uma fase de formulação e tomada de decisões - o processo decisório - e por uma

\footnotetext{
${ }^{1} 0$ presente trabalho foi realizado a partir de discussões realizadas no Núcleo de Pesquisa em Política Externa Latino-Americana (NUPELA) da Universidade Federal da Integração Latino-Americana (UNILA). 0 autor agradece aos membros do NUPELA e aos pareceristas pela contribuição para o aperfeiçoamento do artigo.

2 Doutor em Ciência Política pela UFRGS. Docente do curso de Relações Internacionais da UNILA. Pesquisador do (NUPELA). Foz do Iguaçu/Brasil.
} 
fase de execução. Na América Latina, principalmente após o fim da Guerra Fria e dos governos militares, ocorreu uma diversificação tanto da agenda de política externa como das características dos atores participantes do processo de formulação e execução desta política, mudança que se estendeu aos anos subsequentes.

Neste contexto, no Chile, a partir de 1990, com o final do governo militar, a coalizão de centro-esquerda que governou o país até 2010 reordenou gradualmente a sua chancelaria, criando alguns organismos, suprimindo outros e fortalecendo alguns órgãos existentes. Estes ajustes na política de governo implicaram em uma alteração no papel de alguns órgãos estatais dentro do processo da política externa chilena, em uma fase na qual a emergência de novos atores nos assuntos internacionais passou a ser mais frequente. Entre 2010 e 2014, o governo chileno foi comandado por uma coalizão de centro-direita. Apesar de ideologicamente esta coalizão declarar-se em outro espectro político em relação ao governo anterior, na política externa poucas mudanças ocorreram em relação à agenda e às diretrizes adotadas para sua execução. Houve uma continuidade em temas como comércio, cooperação regional e segurança internacional, através da assinatura de novos tratados de livre comércio, participação em operações de paz e nos foros multilaterais, com regularidade (BRIONES e DOCKENDORFF, 2015). Em termos comerciais, a ação mais substancial do governo de Sebastian Piñera (2010-2014) foi a assinatura e consolidação do tratado da Aliança do Pacífico com o Peru, o México e a Colômbia, um processo de integração com ênfase na área comercial.

Sobre o processo decisório, conforme destacam Bustamante e Rivera (2011), a política exterior chilena historicamente tem sido um espaço do poder executivo, com alguns ministérios e agências mais envolvidos do que outros nas fases de planejamento, formulação e execução. Os autores ressaltam também que as análises sobre a formulação da política exterior chilena têm enfatizado pouco a participação de agentes como o legislativo ou os atores sociais, gerando um vazio bibliográfico, devido à ênfase de estudos sobre o executivo. Os estudos mais relevantes enfocam os principais aspectos do presidencialismo e da centralidade do chefe de Estado na tomada de decisão, dando pouca atenção às outras dimensões do processo decisório (BUSTAMANTE e RIVERA, 2011). Esta escassez de trabalhos acerca da política externa de maneira mais abrangente - sem ênfase somente no executivo - abre espaço para estudos desta natureza.

Este texto insere-se nesta discussão, analisando primeiramente a estrutura 
institucional do processo decisório da política externa do Chile, no intuito de identificar os espaços para a atuação dos atores sociais dentro deste arranjo. Em segundo lugar, analisa-se a fase de formação da Aliança do Pacífico no Chile, em sua etapa inicial, com o objetivo de identificar quais atores sociais estiveram envolvidos no processo. Mais especificamente, a fase entre abril de 2011 e maio de 2013 - respectivamente as datas de assinatura da Declaração Presidencial sobre o tema e de aprovação do processo no legislativo chileno - é o período de referência da análise. Como suporte teórico ao problema de pesquisa, utiliza-se a abordagem de Helen Milner sobre as relações entre grupos de interesse e agentes políticos na política exterior e na política interna.

\section{POLÍTICA EXTERNA EM DOIS NÍVEIS E OS PODERES LEGISLATIVOS}

A teoria, desenvolvida por Helen Milner, utilizada na análise deste texto enquadra-se nos estudos relacionados ao paradigma liberal institucionalista, no que se refere ao seu posicionamento junto às teorias das Relações Internacionais. A abordagem da autora, considerando tanto o nível interno como o externo, além dos diferentes atores e interesses envolvidos, proporciona uma moldura teórico-metodológica útil ao campo da análise de política externa.

Em relação aos dois níveis, interno e externo, Robert Putnam descreve-os como um ambiente no qual, no nível nacional, os grupos domésticos perseguem seu interesse pressionando o governo a adotar políticas favoráveis a seus interesses, enquanto que os atores políticos buscam o poder angariando apoio entre esses grupos. No nível internacional, os governos nacionais buscam maximizar sua capacidade de satisfazer as pressões domésticas, enquanto minimizam as consequências adversas do ambiente externo $^{3}$ (PUTNAM, 2010, p. 151). A esta dinâmica, Putnam denomina Jogos de Dois Níveis, que consistem na ideia de que o corpo político de um Estado joga constantemente na arena política interna e na externa, simultaneamente, tentando alcançar seus objetivos, recebendo pressões diferentes e às vezes contraditórias de ambas as arenas (MILNER, 1997, p. 4). Conforme abordam Rosendorff e Milner, nestas condições, os agentes que participam do processo político são os atores políticos

\footnotetext{
3 Putnam destaca o papel do negociador na fase de barganha. No entanto, pelo fato do foco da análise deste artigo estar na atuação dos atores sociais, não será dada ênfase a este elemento da abordagem do autor.
} 
internos - o executivo e o legislativo -, os grupos de interesse - como atores sociais - e o executivo do outro país com o qual se busca um processo de cooperação (ROSENDORFF e MILNER, 1997, p. 67). Moravcsik (1993, p. 31) destaca que mesmo grupos sociais domésticos podem adotar alianças transnacionais e operar também em dois níveis com atores sociais de outro país.

De acordo com Milner, no âmbito interno, o processo pelo qual passa a definição de um tema de política externa envolve os atores políticos - executivo e legislativo - e os grupos de interesse como atores sociais. Os atores políticos têm como principal interesse angariar votos para obter o êxito eleitoral, que os manterá ou os colocará no poder político. Suas preferências são direcionadas para políticas que gerem melhor condição econômica, com a qual será possível atender aos interesses dos atores sociais, justamente os detentores dos votos. Os atores sociais, por sua vez, possuem interesses específicos, que podem ser das mais variadas índoles, e esperam que sejam atendidos no âmbito decisório da política. Por isto, terão preferência pela adoção de políticas que atendam a estes interesses (MILNER, 1997). Ao mecanismo onde ocorrem as disputas pelo atendimento dos interesses, Milner denomina estrutura de preferências.

O enfoque das questões políticas através de uma estrutura de preferências foi inicialmente concebido por Anthony Downs, cujo padrão apresenta semelhanças com o padrão desenvolvido por Milner, embora cada um dos autores utilize este método para analisar diferentes objetos da política, com diferentes objetivos. Enquanto Downs (2013) demonstrou o comportamento dos atores políticos em um governo democrático, Milner investigou a relação entre as preferências desses atores e a influência de tais preferências no tratamento da política externa. As semelhanças ficam por conta das preferências dos atores e pelo uso das premissas da escolha racional.

Os embates políticos que levam à tomada de decisão em política externa em governos democráticos, guardadas as devidas características de cada modelo institucional, passam pelo processo legislativo antes da ratificação no nível internacional. Matthew Shugart e John Carey analisaram a extensão do poder constitucional do presidente e do poder legislativo do congresso, características que denominaram poderes legislativos (SHUGART e CAREY, 1993). Este termo é utilizado por Lisa Martin para definir os elementos fundamentais à disposição dos agentes políticos no processo decisório da política externa, sendo eles: a) capacidade de 
formação da agenda; b) possibilidade de realizar emendas; c) poder de ratificação ou veto; d) possibilidade de convocação ou de participação em referendos4; e) side payments $^{5}$. Milner utiliza a abordagem de Lisa Martin para desenvolver a ideia do funcionamento da estrutura de preferências e da estruturação de sua teoria. Além disto, destaca que o balanço de poder entre o legislativo e o executivo depende em parte do quanto cada um deles controla estes elementos do processo legislativo (MILNER, 1997, p. 99-109). Para este texto, interessam os três primeiros itens - agenda, emendas e veto - e a possibilidade de influência dos atores sociais.

A agenda refere-se à lista de assuntos que emergem no âmbito político e que devem ser levados em consideração, bem como as alternativas apresentadas para o tratamento de tais assuntos. Um ator com maior poder de agenda pode definir entre alternativas disponíveis e apontar as que são de sua preferência para serem postas na pauta. A capacidade de definir as opções que serão consideradas e a sequência em que serão estruturadas concede um grande poder aos formadores de agenda (MILNER, 1997, p. 102). As emendas são as possibilidades de um ator influenciar mudando as características do tema que está na agenda. Isto significa que um agente que tem o poder de emenda pode alterar o teor de um assunto da agenda, procurando mudá-lo para o ponto mais próximo daquilo que considera a condição ideal (MILNER, 1997, p. 103-104).

Não obstante, deve-se destacar que os agentes políticos estão atentos ao tabuleiro político interno e ao externo simultaneamente, incrementando a importância do poder de veto. A ratificação ou o veto a um tema da agenda são citados por Milner como opostos, sendo o veto o oposto da ratificação. 0 poder de veto é uma característica dos atores políticos cuja aprovação é necessária, mas não suficiente, para a aceitação de um tema da agenda (PEREZ-LIÑÁN e RAGA, 2009, p. 694-695), ou seja, é o poder de um ator de bloquear a adoção de uma política (TSEBELIS, 1995, p. 305). Além da questão da divisão dos votos no parlamento, deve-se abordar o ponto de vista institucional, sobre o qual Milner cita que, na maioria dos regimes presidencialistas, nas questões em que o executivo tem um maior poder de agenda, o legislativo tem algum poder de veto e viceversa (MILNER, 1997, p. 106). Desta forma, o poder de veto em determinadas condições

4 Os referendos no contexto do processo decisório institucional, referem-se aos votos do cidadão, tanto para aprovar como para rejeitar uma política proposta pelo governo (MILNER, 1997).

5 Side payments são uma ampla gama de táticas para obter uma vitória em votação legislativa, através da negociação entre atores do legislativo, com base em elementos como reciprocidade, concessões e ligação entre temáticas parlamentares (MARTIN, 1993). 
funciona como um limitador para o poder de agenda (TSEBELIS, 1995, p. 321), mas dependerá do arranjo institucional vigente.

Sendo assim, o arranjo teórico que se apresenta, a partir da teoria de Helen Milner, considera o processo decisório da política externa como um continuum entre a política doméstica e a política internacional - os dois níveis -, no qual as questões internas envolvidas são tratadas a partir da disputa pelo atendimento de interesses na arena política entre os agentes políticos e os atores sociais - a estrutura de preferências -, sendo que no processo legislativo há mecanismos pelos quais os diferentes atores podem exercer influência - os poderes legislativos. Este é o aporte conceitual que orienta o texto.

\section{ATORES DO PROCESSO DECISÓRIO EM POLÍTICA EXTERNA NO CHILE}

O processo decisório da política externa, assim como frequentemente ocorre com as demais políticas públicas que se tornam leis em democracias representativas, conta com a participação do poder executivo, do poder legislativo e de atores sociais. Eventualmente, há a participação do poder judiciário, o que acontece normalmente em casos excepcionais, não sendo comum que ocorra durante o processo decisório. 0 Chile possui um sistema de governo presidencialista e republicano, com um legislativo bicameral, em um modelo de democracia representativa, que abre espaços para a participação de atores sociais no processo decisório da política externa.

O poder executivo no Chile é liderado pelo Presidente da República, que é o chefe de Estado, auxiliado pelos Ministros de Estado, nomeados pelo presidente, que tratam de temas em áreas específicas e formam o gabinete presidencial. Conforme a Constituição do Chile, em seu artigo 15, é uma atribuição do chefe do executivo conduzir as relações políticas e negociações com outros países e com organismos internacionais, firmando tratados internacionais que estejam de acordo com os interesses do país, submetendo-os à aprovação do legislativo nacional (CHILE, 2009).

No período analisado neste texto, o gabinete possuía 21 ministérios, além do Conselho Nacional de Cultura e Artes e do Serviço Nacional da Mulher, característica que se manteve nas administrações seguintes. Dentre tais ministérios, alguns que participam diretamente da formulação da política externa chilena são os de Economia, Fomento e 
Turismo, Fazenda e o de Agricultura, além do Banco Central (BUSTAMANTE e RIVERA, 2011, p. 361). No entanto, o protagonismo ministerial no processo decisório em política externa está no Ministério de Relações Exteriores, mesmo no que se refere à política econômica comercial, um dos temas mais presentes na política exterior chilena. A estrutura do ministério possui diversas gerências, secretarias e diretorias, dentre as quais se destacam na execução da política externa a Direção Geral de Política Exterior (DIGEN), a Direção Geral de Políticas Consulares e Imigração (DIGECONSU) e a Direção Geral de Relações Econômicas Internacionais (DIRECON).

Dos setores ligados ao executivo, aqueles conjugados às áreas de agricultura, fazenda e economia possuem um caráter essencialmente técnico e de assessoria para as suas respectivas pastas. As diretorias do Ministério de Relações Exteriores, por sua vez, possuem uma natureza mais executiva do que consultiva, tendo uma ligação direta com os assuntos exteriores. Nestas secretarias, ministérios e diretorias, seu trabalho dentro do processo da formulação da política externa permanece longe dos atores sociais, que serão afetados pelas políticas públicas geradas por esta dinâmica, ou seja, não concede poder de agenda aos atores não governamentais.

Entretanto, dentro do processo decisório da política externa do Chile, principalmente na estrutura do executivo, é possível encontrar arranjos institucionais que permitem a participação social, principalmente no que se refere à política externa econômica e comercial. Estes espaços de participação permanente dentro da estrutura estatal, que podem conceder certa capacidade de colocar temas na agenda, são ocupados principalmente pelos setores empresariais.

O principal espaço da participação empresarial é a DIRECON, criada em janeiro de 1979. Trata-se de uma instituição pública ligada ao Ministério de Relações Exteriores, com a função de executar e coordenar a política governamental chilena em assuntos de Relações Econômicas Internacionais. Mesmo que seu decreto de fundação estabeleça que a instituição execute a política formulada pelo Presidente, a DIRECON extrapola seu caráter executor e é marcada pela presença de técnicos e empresários que participam e influenciam a formação da política comercial chilena, tanto pela participação em grupos de trabalhos, negociações bilaterais e multilaterais, como em instituições internacionais. A atuação da DIRECON é focada nos principais espaços da política externa chilena, com uma estrutura estabelecida para atuar em consonância com tal política. 
Ligado à DIRECON está o Instituto de Promoção de Exportações do Chile, o ProChile, órgão que teve importante participação no processo decisório de adesão do Chile à Aliança do Pacífico. 0 ProChile foi constituído em 1974, pelo Decreto 740, como entidade estatal para a promoção das exportações chilenas (CHILE, 1974). À época da criação da agência, esta passou a ser administrada por oito representantes do poder executivo e por cinco membros de entidades privadas ligadas ao comércio. No período em que ocorreram as negociações para a formação da Aliança do Pacífico, o formato do corpo administrativo do ProChile havia sido alterado, passando a ter uma Diretoria Geral, nomeada pelo gabinete de governo, uma Diretoria de Promoção de Exportações, uma Secretaria Executiva do Conselho de Atração de Investimentos Estrangeiros e do Conselho de Indústria e Serviços, além de quatro subdireções: de Desenvolvimento; de Marketing, Comunicações e Marcas; Nacional; Internacional. Outros 25 subdepartamentos alocados nas subdireções completavam a estrutura organizacional (CHILE, 2014, p. 19). Além disto, contava com mais de cinquenta escritórios regionais em todos os continentes.

Apesar de a estrutura administrativa passar a contar apenas com atores estatais, o ProChile não deixou de ser uma instituição com espaço para a participação de atores sociais. Ainda que o planejamento e as ações do ProChile tenham obtido um caráter mais estatal, as atividades realizadas - feiras, oficinas e seminários - se basearam nas necessidades da iniciativa privada para a promoção das exportações. A atividade-fim dos agentes estatais do ProChile, ligada às exportações, junto a a fonte de onde provém as iniciativas, caracterizam estas atividades necessariamente como algo ligado ao nível nacional e ao nível externo, tendo a entidade que estar atenta aos interesses dos atores sociais envolvidos no nível interno.

Em relação ao legislativo nacional chileno, este compõe-se de duas câmaras legislativas, sendo elas a Câmara de Deputados, que possui 120 membros, e o Senado, com 38 componentes, que juntas formam o Congresso Nacional. A principal atribuição do Congresso em relação à política externa é a de aprovar ou rejeitar os tratados internacionais, sendo que estes são apresentados pelo Executivo, para a apreciação das duas instâncias legislativas, de acordo com o artigo 54 da Constituição do país (CHILE, 2009). Matérias de política externa que culminem em tratados internacionais também podem ser propostas pelo legislativo, mas podem ser vetadas pelo Executivo, 
independentemente de seu teor.

As matérias propostas no legislativo são encaminhadas às Comissões Legislativas, que são as instâncias destinadas a organizar o trabalho do legislativo. Montero e López (2002, p. 5), que realizaram um estudo sobre as comissões legislativas na América Latina, definem tais órgãos como grupos de trabalho, temporários ou permanentes, estruturados a partir de áreas temáticas e constituídos por parte dos integrantes de uma assembleia, aos quais se delega parte de suas funções, para promover mais eficiência nos assuntos próprios da função legislativa. O legislativo do Chile possui 18 comissões na Câmara dos Deputados e 19 comissões no Senado.

Quanto às comissões legislativas do Congresso Nacional chileno que tratam da política externa, a Câmara dos Deputados possui a Comissão de Relações Exteriores, Assuntos Interparlamentares e Integração Latino-Americana, composta por treze deputados, enquanto que o Senado opera na análise de matérias de política externa através da Comissão de Relações Exteriores, formada por cinco senadores. 0 papel das comissões não é diferente do papel das demais instâncias semelhantes que tratam de outros temas, sendo responsável por estudar detalhadamente os projetos de lei submetidos à sua análise e posteriormente designar um membro para divulgar o informe sobre o tema à sala de sessões legislativas, onde se procede a votação. As comissões podem convidar atores sociais e do executivo para a participação em suas sessões, tanto para obter esclarecimentos técnicos ou políticos mais específicos acerca dos temas em questão, como para obter e discutir as preferências e inquietações dos grupos interessados na política que está sendo tratada.

Com esta configuração, o legislativo, assim como o executivo e os atores sociais, tem espaço para atuação no processo decisório da política externa chilena, em diferentes medidas a cada fase do ciclo de formulação da política e também em cada área da política. No entanto, afirmar que existem estes espaços não significa que haja equilíbrio por parte da participação ou capacidade de influência destes três atores. Observa-se que a possibilidade de propor a agenda encontra-se disponível apenas aos atores políticos, enquanto que o poder de emenda e o poder de veto encontram-se dentro do espaço das relações entre o executivo e o legislativo, pois após a proposição de um tema na agenda e na tramitação deste, o legislativo pode tanto vetar como emendar ou aprovar uma matéria. 0 executivo não tem a possibilidade de realizar emendas ou vetos durante o 
processo no legislativo, mas pode não ratificar um tema aprovado no legislativo e devolvê-lo às instâncias legislativas. Nesta fase decisória de um tema de política externa, desde a apresentação do tema para ser tratado no legislativo até a ratificação pelo executivo, os atores sociais têm espaço para participação e opinião, mas não possuem poder de veto, emenda ou ratificação. Contudo, considerando a estrutura de preferências de Milner, percebe-se que é possível aos atores sociais atuarem como grupos de pressão, no sentido de terem as suas demandas atendidas, se considerados os interesses dos grupos políticos de angariarem votos para o êxito eleitoral. A análise do processo que culminou na aprovação do tratado da Aliança do Pacífico no Chile permite verificar estas questões.

\section{O PROCESSO INICIAL DA ALIANÇA DO PACÍFICO}

A Aliança do Pacífico é um processo de integração entre Chile, Peru, México e Colômbia, que passou a existir em abril de 2011, quando foi assinada a Declaração de Lima, marcando o início formal da Aliança do Pacífico. Em 4 de dezembro de 2011, em prosseguimento ao previsto na declaração de abril de 2011, foi assinada a Declaração de Mérida, na qual constam os avanços obtidos no processo de integração (DECLARACIÓN..., 2011b). O documento destaca, entre outros pontos a participação de setores privados e grêmios empresariais para a cooperação e o fortalecimento dos negócios e investimentos. No caso do Chile, estas atividades estavam sendo realizadas pelo ProChile. As atividades das quais o ProChile participou foram realizadas conjuntamente com a ProColombia, a ProMéxico e a PromPeru, agências congêneres com objetivos semelhantes, que passaram a integrar o Grupo Técnico de Comércio e Integração, em uma ação que demonstra a atuação do órgão no nível externo. Dentre as iniciativas realizadas pelos órgãos, o ProChile participou em 2011 da abertura da Oficina de Promoção Comercial de Istambul, na Turquia e em feiras internacionais, tais como a Fine Food na India, a Sial na França, a Seoul Food and Hotel na Coreia, a Anuga na Alemanha e a International Travel Fair em Taiwan (CHILE, 2014, p. 131).

Analisando-se a participação do ProChile em edições anteriores em eventos como a Seoul Food and Hotel de 2012, ocorrida em maio daquele ano, é possível constatar o caráter do órgão e o seu papel na formação da política externa, como ligação 
entre a burocracia estatal e os atores sociais, neste caso, notadamente o setor empresarial local, ou seja, em nível interno. O ProChile emitiu uma convocatória para empresas interessadas em participar da feira coreana, com informações gerais sobre a Coreia, destacando as oportunidades de projeção do mercado chileno no país. Foram expostas as características específicas da feira e as normas para que as empresas apresentassem suas propostas de participação no evento (CHILE, 2013b). A convocatória seguiu o previsto nos decretos ministeriais, nos ofícios da direção do ProChile, nas resoluções da DIRECON e da Controladoria Geral da República (CHILE, 2012), ligando assim os participantes privados às regras estatais. Como resultado, sete empresas privadas participaram do evento, recebendo o apoio do escritório regional do ProChile na Coreia do Sul. Após estas ações, o empresariado organizado passou a atuar na formação da Aliança do Pacífico.

Em agosto de 2012 foi constituído o Conselho Empresarial da Aliança do Pacífico (CEAP), formado por 14 empresários dos quatro países, sendo quatro do Peru, quatro do México, três da Colômbia e três do Chile ${ }^{6}$. De acordo com o documento constitutivo do conselho, trata-se de um grupo de empresários que, de forma individual e voluntária, acordam constituir-se promotores da Aliança do Pacífico, com base no disposto na Declaração de Mérida e no Acordo Marco. Além disto, o documento que constituiu o CEAP descreve, como resultado da primeira reunião do órgão, que este apresentaria aos ministros de Relações Exteriores e de Comércio Exterior dos países da Aliança do Pacífico uma declaração contendo o reconhecimento do CEAP à iniciativa, o apoio do organismo a este processo de integração, o objetivo de alcançar as metas previstas e o compromisso de dar prosseguimento ao que foi decidido nas cúpulas presidenciais anteriormente realizadas (CEAP, 2012).

A CEAP era a principal representante, dentro da Aliança, da Confederação da Produção e do Comércio (CPC) do Chile, a maior organização empresarial do país. Fundada em 1935, a CPC reúne os principais setores produtivos chilenos. Nas décadas de 1940 e 1950, o presidente chileno, Jorge Alessandri, era membro da CPC, tendo sido inclusive o presidente da confederação. Na fase desenvolvimentista dos anos 1960, a CPC foi uma crítica das medidas propostas pela CEPAL para a América Latina. No

\footnotetext{
6 Os empresários chilenos foram Lorenzo Leocadio Constans Gorri, Jorge Errázuriz e Juan Eduardo Errázuriz. Posteriormente, incorporou-se também o empresário John Graell (CPC, 2012, p. 62).
} 
período de governo militar (1973-1990), diversas agremiações empresariais tentaram influenciar a política externa, mas somente a CPC conseguiu ter diversos de seus membros nomeados em ministérios pelo presidente Pinochet. Ao final do governo militar, a CPC firmou acordos com sindicatos trabalhistas com o intuito de promover a estabilidade social no novo regime (MONTEIRO, 1993).

Estes são alguns exemplos que demonstram que a CPC sempre foi um órgão ativo dentro da arena política chilena e que no caso da Aliança do Pacífico estaria apenas cumprindo sua função histórica, não havendo nenhuma mudança de rumo, apenas um prosseguimento do papel desta instituição como ator social no processo decisório da política externa. Na Declaração Conjunta dos Presidentes da XXII Reunião Presidencial da Aliança do Pacífico, os chefes de Estado destacaram como um avanço e consideraram bem-vinda a formação do CEAP, afirmando que o órgão permitiria a vinculação do setor privado ao processo de integração (DECLARACIÓN, 2012).

Em janeiro de 2013, o CEAP apresentou aos Ministros de Estado envolvidos na Aliança do Pacífico a Declaração do Conselho Empresarial da Aliança do Pacífico. Neste documento, primeiramente os empresários destacaram que estavam cientes dos avanços realizados pelos governos envolvidos na Aliança do Pacífico e que expressavam seu reconhecimento a tais governos pelo que estava construído. A seguir, afirmavam que por conta dos avanços nas ações governamentais, o CEAP sentiu-se motivado a impulsionar seus trabalhos para contribuir com o alcance das metas da Aliança e que possuía uma agenda de trabalho para o primeiro semestre de 2013, voltada para temas como mobilidade de pessoas, promoção comercial, educação em áreas técnicas e homologação de normas tributárias. 0 objetivo de tal agenda de trabalho era colocar à disposição dos governos as conclusões e discussões da classe empresarial sobre estes temas, bem como fortalecer a comunicação e o trabalho conjunto do empresariado de cada país com seus respectivos governos, a fim de associar os esforços dos setores público e privado, para a obtenção de melhores resultados (CEAP, 2013).

Em relação aos atores sociais, nota-se ainda que em uma primeira fase apenas participaram de algumas ações propostas e coordenadas por órgãos do poder executivo - DIRECON e ProChile - através de licitações, cujas regras e premissas foram previamente estabelecidas pelos corpos técnicos e diplomáticos destas agências. No entanto, com a evolução das negociações e da institucionalização da Aliança no campo 
político, o empresariado demonstrou que não seria somente um ator passivo no processo, mas que tinha o intuito de se organizar para participar da formulação e do processo decisório das políticas, como exemplificado com a constituição do CEAP. 0 fato de que o empresariado apresentou seu apoio ao governo e desenvolveu uma agenda de trabalho, mesmo antes do processo ser submetido à apreciação do poder legislativo, demonstrou o interesse deste ator social. Todavia, entre abril de 2011 e dezembro de 2012 as decisões político-institucionais tomadas foram centralizadas no executivo.

Resta ainda outra observação sobre o empresariado, como ator social. Conforme verificado na composição do CEAP e nas ligações dos empresários envolvidos com outros órgãos de representação, bem como na longevidade de tais órgãos - aqueles ligados à CPC - a classe empresarial chilena possui uma tradição de organização e participação no processo político. Sendo assim, em um primeiro momento participou sem propor medidas que evidenciassem suas preferências, mas em um segundo momento passaram a agir mais ativamente, cumprindo seu papel histórico na política do Chile. Ressalta-se ainda que o CEAP funcionou para os empresários chilenos - os atores sociais em questão - como uma aliança transnacional fora do âmbito político, dentro da qual foi realizada a passagem dos empresários de atores sociais passivos para entes propositivos dentro do processo de cooperação internacional, a despeito das decisões políticas serem prerrogativas do executivo e do legislativo. O CEAP envolveu, além do grêmio empresarial chileno, também o Conselho Empresarial Mexicano de Comércio Exterior, Investimento e Tecnologia, a Associação Nacional de Empresários da Colômbia e a Sociedade de Comércio Exterior do Peru. As associações empresariais chilenas, ao se pronunciarem através do CEAP com a Aliança do Pacífico e ao mesmo tempo participarem, através da CPC, das atividades propostas pelo executivo chileno, consolidaram a participação de um ator social em dois níveis. Assim, apesar do empresariado como ator social não possuir poder de agenda dentro do arranjo institucional no Chile, exerceu influência no processo decisório por outras formas?

Considerando também o papel do ProChile e de seus congêneres nos demais países, bem como a atuação do empresariado chileno e dos outros Estados da Aliança, os

$7 \quad$ No final de maio de 2013, a CEAP apresentou sua agenda de trabalho à Aliança e foi designado um grupo de trabalho para analisar as reivindicações. Os resultados gerados pela agenda e pelo grupo de trabalho não são aqui analisados devido ao escopo deste artigo, que se centra na fase do processo decisório. Este tema faz parte de outra fase desta pesquisa, que analisa a execução e o controle da Política Externa. 
atores sociais encontram ainda maior relevância. Esta assertiva deve-se ao fato de que a partir de 2012 uma das prioridades dos empresários, por solicitação dos agentes políticos dos respectivos governos, tem sido a identificação das principais problemáticas e situações envolvidas no fortalecimento comercial da Aliança. Além disto, com o passar do tempo, o ProChile, o ProColombia, a ProMéxico e a PromPeru passaram a ter a incumbência de apoiar o empresariado em suas demandas, com o objetivo de que "o setor privado, de maneira consensual nos quatro países, gere propostas viáveis aos governos em prol da integração" (PWC MÉXICO, 2014, p. 10). Apesar da inexistência de poderes legislativos formais aos atores sociais durante a tramitação do processo no legislativo, este avanço no protagonismo em apresentar as demandas evidencia o quanto estes atores podem influenciar no processo de formulação da política comercial chilena.

\section{ALIANÇA DO PACÍFICO NO LEGISLATIVO CHILENO}

Em 7 de janeiro de 2013, o processo foi submetido na Câmara dos Deputados pelo ministro de Relações Exteriores e pelo ministro de Economia, Fomento e Turismo e em 24 de janeiro de 2013 foi encaminhado à Comissão de Relações Exteriores, Assuntos Interparlamentares e Integração Latino Americana. A sessão do dia 2 de abril da comissão contou com os representantes do legislativo e com atores sociais, sendo eles: Fundação Jaime Guzmán, representada pelo advogado Máximo Pavez Cantillano; Fundação Chile 21, representada pelo diretor de seu programa internacional, Cristián Fuentes Vera; Instituto Igualdad por seu presidente Ricardo Núñez Muñoz; Instituto de Ciencias Alejandro Lipschutz (ICAL), através de Marcos Barraza Gómez, diretor executivo; Fundación Chilena del Pacífico, representada pelo presidente Francisco Silva Silva e pelo secretário executivo Manfred Wilhelmy von Wolff (CHILE, 2013c, p. 71).

A participação dos atores sociais na sessão da comissão atende tanto a uma premissa normativa regimental como a um aspecto teórico analítico. De acordo com as normas de funcionamento das comissões, estas podem convidar atores sociais e do executivo para participarem dos trabalhos com esclarecimentos ou expressando opiniões sobre as temáticas tratadas, o que atende uma norma do regimento institucional. Também pode abrir espaço para os atores sociais realizarem manifestações que venham a gerar emendas ou indicar aos parlamentares a sua 
preferência pelo veto de um determinado tema, não caracterizando um direito de veto ou emenda, mas um espaço para participação social no processo da política externa e possível espaço de influência.

Em relação aos atores não governamentais que participaram da sessão, é importante verificar quais são as suas principais características e como foram seus pronunciamentos na comissão legislativa. A Fundação Jaime Guzmán é uma instituição sem fins lucrativos, fundada em 1991, com o objetivo de elaborar e discutir ideias que possam se materializar em políticas públicas, como forma de contribuir com o desenvolvimento do país (FUNDACIÓN JAIME GUZMÁN, 2015). Esta instituição está ligada à União Democrática Independente, a UDI, (GARCÉ, 2009, p. 56), partido político de centro-direita e defensor dos postulados de uma economia liberal, que fazia parte da base de apoio do presidente chileno Sebastian Piñera no período da formação da Aliança do Pacífico, agindo como um think tank formador de quadros políticos dos partidos de direita chilenos (TORO e COCIÑA, 2009, p. 110-121).

A Fundação Chilena do Pacífico foi fundada em 1994, com o objetivo de coordenar as ações de agentes públicos e privados na inserção internacional do Chile na região Ásia-Pacífico. As ações da fundação ocorrem através do assessoramento em ações que fomentem o intercâmbio comercial, cultural, econômico e científico na Cuenca del Pacífico, desenvolvendo estudos para o maior conhecimento dos países da região, bem como suas características sociais e culturais, além de analisar os tratados bilaterais existentes de tais países com o Chile. Participam das atividades da fundação, na categoria de sócios, atores governamentais como a DIRECON e o Banco Estado de Chile, além de empresas privadas dos setores automotivo, bancário, aviação, mineiro e outros (FUNDACIÓN CHILENA DEL PACÍFICO, 2015).

A Fundação Chile 21 é semelhante à Fundação Jaime Guzmán, mas opera em outro espectro ideológico. Fundada em 1992, com o intuito de fortalecer o pensamento de esquerda e progressista, dialogando com todos os setores públicos, sem discriminação partidária, a Chile 21 atua em rede com instituições congêneres como a Fundação Perseu Abramo, do Brasil, a CEPES da Argentina e a uruguaia Fundación Liber Seregni (FUNDACIÓN CHILE 21, 2015). Esta fundação foi instaurada pelos partidos que compunham a Concertación, uma coalizão de partidos de esquerda e centro-esquerda, que governou o Chile entre 1990 e 2010 e que compunha a oposição ao governo central 
no período das negociações da Aliança do Pacífico. De acordo com Adolfo Garcé, a Chile 21 foi uma das instituições que mais contribuíram para a formação do programa partidário dos partidos da Concertación para o ano de 2009 (GARCÉ, 2009, p. 41). Uma particularidade da Chile 21 é uma linha de trabalho permanente destinada ao estudo da dimensão internacional da política, denominada Programa Internacional.

O Instituto Igualdad é uma fundação de direito privado criada pelo Partido Socialista (PS) do Chile no período da consolidação democrática, no início do século XXI, considerado na classificação de Toro e Cociña como um agente partidário, destinado a formar agentes políticos para o partido (TORO e COCIÑA, 2009). 0 órgão desenvolve atividades tais como seminários e oficinas de trabalho, além de produzir publicações destinadas a contribuir com o fortalecimento das instituições democráticas, realizando tais atividades de maneira individual ou em parceria com instituições semelhantes ou com órgãos estatais (INSTITUTO IGUALDAD, 2015).

O Instituto de Ciências Alejandro Lipschutz (ICAL) foi fundado em 1983 pelo Partido Comunista, com o objetivo de contribuir para a defesa de um pensamento crítico no período do governo Pinochet. Em suas primeiras etapas de atuação, desenvolveu atividades integrando o ensino, a pesquisa e a extensão, pilares da academia, preenchendo uma lacuna existente nas universidades na fase de governo militar, atraindo intelectuais, estudantes e trabalhadores. Ainda antes de 1990, passou a trabalhar em conjunto com outros órgãos semelhantes, como o Programa de Economia do Trabalho (PET), Grupo de Investigações Agrarias (GIE) e o Programa Interdisciplinar de Investigação em Educação (PIIE), agrupados na Academia de Humanismo Cristiano, agindo na política pela via acadêmica (TORO e COCIÑA, 2009, p. 100).

Os pronunciamentos destes cinco atores sociais dividiram-se em dois grupos. Um deles, formado pela Fundação Jaime Guzmán e pela Fundação Chilena do Pacífico, declarou apoio à iniciativa, destacando que a economia dos países da região está fortemente atrelada à economia chinesa e das outras grandes potências globais, sendo que o desempenho do desenvolvimento dos países da região depende muito da capacidade de resposta às mudanças na economia mundial. Citaram ainda que o acordo estava em consonância com estas questões, pois tinha em sua base a liberalização comercial e o respeito aos tratados de livre comércio existentes e era uma forma de responder à irrupção da região Ásia-Pacífico na economia mundial, bem como contra 
arrestar o avanço chinês na região. Por fim, afirmaram que o tratado não geraria fricções com o Brasil e que está em acordo com os interesses nacionais, além de frisarem que se tratava de uma iniciativa realista, baseada na afinidade das políticas exteriores dos países fundantes, não havendo nenhuma carga ideológica (CHILE, 2013c, p. 72-73).

O ICAL, o Instituto Igualdade e a Chile 21 posicionaram-se de forma crítica, afirmando que se trata apenas do aparelhamento de um grupo político e ideológico, pois somente aceita membros que possuam as mesmas visões sobre a política econômica e comercial. Declararam ser preocupante a ausência de uma política latino-americana no Acordo Marco, o que reforçava mais ainda o componente ideológico, pois não abre novos mercados - os parceiros da Aliança são aqueles com os quais existiam tratados de livre comércio - e não fortalece a economia regional, pois exclui o Brasil e a Argentina. Afirmavam, assim, que era uma iniciativa excludente (CHILE, 2013c, p. 72-74).

Após três sessões, o tema foi votado em 9 de abril de 2013 pelos parlamentares da comissão, tendo obtido oito votos a favor e três abstenções. Em 30 de abril o tema foi apresentado pela comissão no plenário da Câmara dos Deputados e submetido à votação, recebendo 66 votos a favor, 2 votos contra, com 14 abstenções (CHILE, 2013d, p. 43). Com este resultado, finalizou-se o procedimento na Câmara dos Deputados, sendo o processo encaminhado ao Senado exatamente com o mesmo teor com o qual chegou à Câmara. No Senado, a proposição foi discutida na 23a Sessão da Comissão de Relações Exteriores, em 14 de maio de 2013, com a presença do Ministro de Relações Exteriores e do Diretor da DIRECON, sem presença de atores não governamentais (CHILE, 2013e). Após breve discussão, o processo foi aprovado por unanimidade pelos senadores da comissão e posteriormente na sessão plenária, em votação de quórum simples. Com a emissão em 23 de maio de 2013 do Ofício no 10.747 (CHILE, 2013f), finalizou-se o processo de aprovação do Acordo Marco da Aliança do Pacífico no legislativo do Chile.

Dentro do processo legislativo, os atores sociais tiveram espaço de manifestação e de debate de seu posicionamento em relação ao tratado. Todavia, o conteúdo aprovado pelo legislativo não sofreu alterações, apesar de alguns destes atores, os discordantes, terem apresentado os pontos que consideravam problemáticos. A única influência clara foi a de se realizar uma sessão extra da comissão com a presença de representantes do executivo para o esclarecimento dos pontos onde havia discordância. Porém, verificouse que o debate no legislativo ocorreu na direção da defesa da proposta pelos grupos 
mais próximos do partido governista, com críticas por parte dos oposicionistas.

Entretanto, não se pode afirmar que este espaço de ação dos atores sociais não possa produzir algum tipo de influência. No caso estudado, tanto os atores sociais que se pronunciaram contra o tratado como os parlamentares contrários compunham uma minoria, o que influenciou na decisão final. Porém, à luz da estrutura de preferências de Milner e de Downs, nos casos em que haja uma oposição da maioria dos atores sociais participantes em relação à aprovação de um tratado, eleva-se o custo da aprovação do tratado para os atores políticos envolvidos, pois isto pode custar votos e comprometer seus interesses políticos imediatos. Sendo assim, o fato de não ter havido mudanças no projeto inicial, a despeito do descontentamento de parte dos atores sociais, não significa que o espaço de participação social no processo decisório de política externa não possa gerar algum tipo de influência efetiva em outros casos.

\section{Considerações finais}

O período analisado neste texto apresentou uma primeira fase, de abril de 2011 a dezembro de 2012, marcada pela institucionalização da Aliança do Pacífico entre os executivos dos países envolvidos. Logo após, houve uma segunda fase, de janeiro a maio de 2013, quando ocorreu o trâmite do processo legislativo no Chile.

Verificou-se que em ambas as fases houve a participação de atores sociais. Na primeira fase do processo decisório, inicialmente, a participação dos empresários em ações coordenadas pelo executivo - como em feiras internacionais - recebendo apoio dos entes governamentais e concorrendo à participação em editais de livre concorrência. Posteriormente, os empresários organizaram-se em um conselho específico para tratar de temas relacionados à Aliança do Pacífico, apoiando a iniciativa governamental, mas demonstrando que passariam a propor agendas e temas, sendo mais ativos e menos passivos. Na segunda fase, do trâmite legislativo, os atores sociais participantes tiveram um caráter muito diferente do empresariado que havia buscado mais espaço anteriormente. Nas sessões legislativas participaram think tanks ligados a partidos políticos e instituições vinculadas à academia, além de um órgão de assessoria do governo. Apesar das discussões nas quais participaram, as indagações realizadas pelos atores sociais na fase legislativa não geraram alterações no documento final. 
Constatou-se que o empresariado chileno, como ator social, executou seu jogo tanto no nível interno através das ações da CPC como no nível externo com a CEAP. Além disto, ganhou protagonismo na etapa de execução da política externa, quando as agências estatais de promoção de exportações passaram a atuar em função das demandas dos atores sociais. Neste ponto, na prática, os atores sociais passaram a exercer certo poder de agenda, que não é encontrado dentro do arranjo institucional pelo qual passam os tratados internacionais no âmbito político. Os atores sociais não demonstraram poder de emenda ou poder de veto dentro do processo legislativo, ficando estas prerrogativas concentradas na relação entre executivo e legislativo dentro do processo decisório.

Após a aprovação no legislativo, a Aliança do Pacífico ganhou um novo dinamismo no Chile, caracterizando assim o avanço do processo de execução da política externa e o fim da etapa decisória.

\section{REFERÊNCIAS}

BRICEÑO-RUIZ, J. La Iniciativa del Arco del Pacífico Latinoamericano. Revista Nueva Sociedad, jul-ago 2010.

BRIONES, S.; DOCKENDORFF, A. Continuidad y cambio en la política exterior chilena en el gobierno de Sebastián Piñera (2010-2014). Estudios Internacionales, n. 180, p. 115138, 2015.

BUSTAMANTE, G. A.; RIVERA, J. R. Los actores de la Política Exterior: el caso del Congreso Nacional de Chile. Polis, Santiago, v. 28, n. 10, p. 359-392, 2011.

CEAP. Constitución del Consejo Empresarial de la Alianza del Pacífico. Ciudad del México: CEAP, 2012.

CEAP. Declaración del Consejo Empresarial de la Alianza del Pacífico. Santiago: CEAP, 2013.

CHILE. Decreto Ley no 740 - Crea el "Instituto de Promoción de Exportaciones de Chile" (PROCHILE). Ministerio de Economia, Fomento y Reconstrución. Santiago. 1974.

CHILE. Constitución Política de la República de Chile (actualización octubre 2009). Santiago: [s.n.], 2009.

CHILE. Memoria Anual Ministerio de Relaciones Exteriores 2011. Archivo General Histórico. Santiago: MinRel. 2011.

CHILE. Resolución Exenta no J-48: adjudica cupos feria Seoul Food \& Hotel 2012. Direcon. 
Santiago: MinRel. 2012.

CHILE. Sesión 132ạ en jueves 24 de enero de 2013. Cámara de Diputados. Santiago. 2013. CHILE. Ficha Seoul Food \& Hotel 2013. Direcon. Santiago: MinRel. 2013b.

CHILE. Sesión 15ạ en martes 16 de abril de 2013. Santiago: Cámara de Diputados. 2013c. CHILE. Sesión 20ạ en martes 30 de abril de 2013. Santiago: Cámara de Diputados. 2013d.

CHILE. Informe de la Comisión de Relaciones Exteriores: Boletín 8801-10, Santiago, 2013e. Disponivel em:

<http://www.senado.cl/appsenado/templates/tramitacion/index.php?boletin_ini=880 1-10>. Acesso em: 27 dezembro 2015.

CHILE. Oficio $n^{\circ}$ 10.747. Valparaíso: Cámara de Diputados. $2013 \mathrm{f}$.

CHILE. Memoria ProChile 2010-2014. Santiago: Depto. de Prensa, 2014.

CPC. Memoria Anual 2011-2012. Santiago: CPC, 2012.

CPC. Memoria 2013-2015. Santiago: CPC, 2015.

DECLARACIÓN CONJUNTA DE LOS PRESIDENTES DE A ALIANZA DEL PACÍFICO. XXII Cumbre Iberoamericana. Cádiz: [s.n.], 2012.

DECLARACIÓN DE MÉRIDA. II Cumbre de la Alianza del Pacífico. Mérida: [s.n.]. 2011b.

DOWNS, A. Uma teoria econômica da democracia. Tradução de Sandra G. T. Vasconcelos. São Paulo: EDUSP, 2013.

FUNDACIÓN CHILE 21. Memoria 2008. Santiago: Chile 21, 2009.

FUNDACIÓN CHILE 21. História, 2015. Disponivel em:

<http://www.chile21.cl/historia/>. Acesso em: 23 dezembro 2015.

FUNDACIÓN CHILENA DEL PACÍFICO. Nosotros, 2015. Disponivel em:

<http://www.funpacifico.cl/>. Acesso em: 12 dezembro 2015.

FUNDACIÓN JAIME GUZMÁN. Qué hacemos?, 2015. Disponivel em:

<http://www.jaimeguzman.cl/que-hacemos>. Acesso em: 22 dezembro 2015.

GARCÉ, A. Estudio marco. In: MENDIZABAL, E.; SAMPLE, K. Dime a quién escuchas. think tanks y partidos políticos en América Latina. Lima: IDEA, 2009. p. 23-58.

ICAL. Historia, 2015. Disponivel em: <http://www.ical.cl/quienes-somos/historia/>. Acesso em: 12 dezembro 2015.

INSTITUTO IGUALDAD. Quienes somos, 2015. Disponivel em:

<http://institutoigualdad.cl/quienes-somos>. Acesso em: 12 dezembro 2015.

LERCARI, R. B. La Alianza del Pacífico: ¿Hacia dónde vamos? In: INSTITUTO, K. A.; IDEI; UNIVERSIDAD DE CHILE Generación de Diálogo Chile-Perú / Perú-Chile. Lima: Equis Equis, 2011. Cap. 3, p. 39-56.

MARTIN, L. Credibility, costs and institutions: cooperation on economic sanctions. World Politics, 45, n. 3, 1993. 406 - 432. 
MILNER, H. International theories of cooperation among nations: strengths and weaknesses. World Politics, 3, 1992. 466-496.

MILNER, H. V. Interests, institutions and information: domestic politics and international relations. New Jersey: Princeton University Press, 1997.

MONTEIRO, C. El actor empresarial en transición. Colección Estudios Cieplan, Santiago, v. 37, n. 1, p. 37-68, junho 1993.

MONTERO, M. G.; LÓPEZ, F. S. Las comisiones legislativas en América Latina: una clasificación institucional y empírica. Working Paper nํ2ㅇ. 212. Barcelona: ICPS. 2002.

MORAVCSIK, A. Integrating international and domestic theories of international bargaining. In: EVANS, P. B.; JACOBSON, H. K.; PUTNAM, R. D. Double-edged diplomacy: international bargaining and domestic politics. California: University of California Press, 1993. p. 3 - 42.

PEREZ-LIÑÁN, A.; RAGA, J. C. R. Veto players in presidential regimes: institutional variables and policy change. Revista de Ciência Política, 29, n. 3, 2009. 693 - 720.

PUTNAM, R. Diplomacia e política doméstica: a lógica dos jogos de dois níveis. Revista de Sociologia e Política, 36, n. 18, 2010. 147 - 174.

PWC MÉXICO. La Alianza del Pacífico: una nueva era para América Latina. Cidade do México: Pricewaterhouse Coopers México, 2014. Disponivel em:

<https://www.pwc.com/mx/es/publicaciones/archivo/2014-10-alianza-pacificobaja.pdf>. Acesso em: 26 maio 2016.

ROSENDORFF, P. B.; MILNER, H. A model of two-level game. In: MILNER, H. Interests, institutions, and information: Domestic politics and international relations. New Jersey: [s.n.], 1997. p. 67-98.

SHUGART, M.; CAREY, J. Presidents and Assemblies: Constitutional Design and Electoral Dynamics. New York: Cambridge University Press, 1993.

SILVA, J. A. Processo constitucional de formação das leis. São Paulo: Malheiros, 2006.

TORO, S. Conducta legislativa ante las iniciativas del Ejecutivo: unidad de los bloques políticos en Chile. Rev. cienc. polít. (Santiago), Santiago, v. 27, n. 1, p. 23-41, 2007.

TORO, S.; COCIÑA, M. Los think tanks y su rol en la arena política chilena. In: MENDIZABAL, E.; SAMPLE, K. Dime a quién escuchas. think tanks y partidos políticos en América Latina. Lima: IDEA, 2009. p. 98-126.

TSEBELIS, G. Decision making in political sYstems: veto players in presidentialism, parliamentarism, multicameralism and multipartidarism. British Journal of Political Science, 25, 1995. 289 - 325.

VAN KLAVEREN, A. La política exterior de Chile durante los gobiernos de la Concertación (1990-2010). Estudios Internacionales, n. 169, p. 155-172, 2011.

VERDEJO, I. P. Chile. In: SÁEZ, M. A.; FREIDENBERG, F. Partidos Políticos de América Latina - Cono Sur. Salamanca: Ediciones Universidad Salamanca, 2002. p. 245-329. 